\title{
Violent Video Games Induce an Affect Processing Bias
}

\author{
Steven J. Kirsh, Paul V. Olczak, and Jeffrey R. W. Mounts \\ State University of New York-Geneseo
}

\begin{abstract}
This study investigated the effects of violent video game play and trait hostility on attentional bias toward negatively valenced words. Following video game play, participants completed an emotional Stroop task. Results indicated greater Stroop interference for participants high in trait hostility and for participants playing violent video games. Implications of these findings are discussed with respect to current models of aggressive behavior.
\end{abstract}

For nearly 30 years, video game play (on either computers or video game consoles) has been one of the most popular leisure activities for adolescents (Cesarone, 1998). Currently, the video game industry grosses nearly $\$ 10$ billion annually (Klinkenborg, 2002). Due in part to a rash of school shootings, however, the effects of violent video games have recently come under scientific, public, and political scrutiny. For instance, several of the leading researchers in the field recently testified before a U.S. Senate Commerce Committee hearing about the deleterious effects of violent video games on children and adolescents (e.g., Anderson, 2000; Funk, 2000). Although the impact of media violence has been underreported by news services (Bushman \& Anderson, 2001), research has consistently found that exposure to violent media appears to increase aggressive behavior, thoughts, and feelings in children, adolescents, and young adults (Anderson \& Bushman, 2001). This connection has been found using both correlational (e.g., Fling et al., 1992; Griffiths \& Hunt, 1995) and experimental (e.g., Anderson \& Dill, 2000; Ballard \& Lineberger, 1999) methodologies.

Recently, Anderson and Bushman's (2002) General Aggression Model (GAM) has been developed, in part, to account for the effects of violent video games on aggressive behavior. According to the GAM, person factors (e.g., trait hostility, atti-

Requests for reprints should be sent to Steven Kirsh, State University of New York-Geneseo, Department of Psychology, Geneseo, NY 14454. E-mail: kirsh@geneseo.edu 
tudes toward violence) and situational factors (e.g., exposure to real-world or media violence) influence an individual's present internal state. Within an individual's internal state, cognitions (e.g., aggressive scripts, hostile thoughts), affects (e.g., hostile feelings), and arousal (e.g., heart rate, blood pressure) influence one another. For example, hostile cognitions can increase hostile feelings (an affect). Subsequently, cognitions, affects, and arousal interrelate to influence an individual's interpretation of an aggressive act (e.g., harm doer has hostile or benign intent). Once an interpretation has been made (i.e., harm doer had benign or malevolent intent), decision-making processes (e.g., aggress, ignore) lead to the onset of thoughtful or impulsive action. The behavior and response to that behavior operate in a feedback loop, subsequently affecting situational and person factors.

When activated, present internal state variables may affect the processing of new information by creating an attentional bias for mood congruent information. Thus, emotional stimuli of a valence similar to that of activated cognitive internal state variables should be attended to in greater detail. The association between affect and cognition has been assessed by numerous researchers using a modification of the Stroop color-naming task (Stroop, 1935). This modified procedure, known as an "emotional Stroop," requires that participants identify the color of emotionally laden and nonemotionally laden words as quickly as possible (see Eckhardt \& Cohen, 1997). The difference in reaction time (RT) between these two word types represents the degree to which the content of the words (e.g., emotionally laden vs. neutral) affects attentional resources. Thus, we might expect a processing bias to render emotionally congruent words more salient and therefore more difficult to ignore.

According to Sharma and McKenna (2001), numerous studies, in both clinical and nonclinical samples, have demonstrated that emotionally laden words that correspond to the emotional state of the participant produce greater interference (i.e., longer response latencies) than neutral words. For instance, individuals high in trait anxiety demonstrate an emotional Stroop effect for words related to threat (Egloff \& Hock, 2001). Similarly, Eckhardt and Cohen (1997) found that, after being insulted by a study confederate, participants high in trait anger demonstrated longer response latencies to anger words than neutral words. Of note, no such effects were seen for individuals completing the emotional Stroop task that were not insulted by the study confederate. Thus, in addition to personality characteristics affecting the processing of emotionally laden words, situational influences may also produce attentional biases.

According to the GAM, violent video games influence aggressive behavior through short-term and long-term effects. In the short term, violent video games function as a situational factor, resulting in an increase in aggressive cognitions, affects, and arousal. Anderson and Bushman (2001) recently produced a meta-analytic review that provides empirical support for the contention that violent video games lead to aggressive behavior (average effect size, $r_{+}=.19, p<.05$ ), aggres- 
sive cognitions (average effect size, $r_{+}=.27, p<.05$ ), hostile affects (average effect size, $r_{+}=.18, p<.05$ ), and increased physiological arousal (average effect size, $\left.r_{+}=.22, p<.05\right)$. In the long term, violent video games are hypothesized to influence aggressive behavior by promoting aggressive beliefs and attitudes and creating aggressive schema, aggressive behavioral scripts, and aggressive expectations, as well as desensitizing individuals to aggression. In turn, these factors bias an individual's personality toward aggression (Anderson \& Bushman, 2001).

Although both situational and person variables are viewed as significantly contributing to aggressive behavior, few studies assessing the effects of violent video games (a situational factor) on cognitive processes associated with aggression have concomitantly evaluated the contribution of person factors such as trait hostility. Furthermore, the studies that have been conducted have produced contradictory results. For instance, Anderson and Dill (2000) found moderating effects of trait hostility on the impact of violent video games in a correlational assessment (Study 1), but no such moderating effects of trait hostility were evident in their experimental procedure (Study 2). Similarly, whereas Irwin and Gross (1995) failed to find a moderating effect of trait impulsivity and violent video games for children in middle childhood, Lynch, Gentile, Olson, and van Brederode (2001) found an additive effect of trait hostility and violent video game exposure in early adolescence. Given the paucity of research and inconsistency of findings, additional assessments on the moderating or additive effects of trait hostility and violent video game exposure are warranted.

The purpose of this study is to examine whether a processing bias for negatively valenced emotional stimuli in the Stroop task occurs as a result of (a) violent video game play and (b) trait hostility. For this study, exposure to violent video games should activate present internal state variables, potentially influencing participants' RTs during the emotional Stroop task. Thus, it is hypothesized that individuals exposed to violent video games will show evidence of attentional bias and produce a greater Stroop effect than individuals exposed to nonviolent video games. Furthermore, based on previous research linking trait hostility to attentional biases (Eckhardt \& Cohen, 1997), we expect to find that participants high in trait hostility will demonstrate a greater Stroop effect than individuals low in trait hostility. Finally, it should follow that those high in trait hostility exposed to violent video games should demonstrate the greatest attentional bias relative to the other groups.

\section{METHOD}

Participants were 129 introductory psychology students (56\% women, 91\% White) at a public liberal arts college in western New York state. The distribution of men and women in this study approximated the gender distribution at the col- 
lege. Participants received extra credit for participation in each component of this study.

\section{Procedure}

At the beginning of the semester, participants filled out the Buss-Durkee Hostility Inventory (BDHI; Buss \& Durkee, 1957) to assess their trait level of hostility. Under the premise that a new research opportunity was available, approximately 6 to 10 weeks after completing the BDHI, these participants were recruited to participate in the video game portion of the study. Research assistants, blind to the participant's trait hostility scores, randomly assigned participants to one of two conditions: violent and nonviolent. Participants in the violent condition played a video game with a high degree of violence and gore. Participants in the nonviolent condition played a nonviolent video game. Following video game play, the Genov Modified Stroop Task (GMST; Genov, Shay, \& Boone, 2002) was used to test for cognitive interference in categories of words using the Stroop automatic processing paradigm. To familiarize participants with the GMST (see following), and thus reduce error, an 8-word (4 neutral, 4 negatively valenced) version of the emotional Stroop task was administered. Following the brief (less than $2 \mathrm{~min}$ ) training period, the 40-word emotional Stroop task was conducted. Participants were excluded from the study if their performance on the GMST resulted in an error rate greater than $20 \%$. Based on criterion, 12 participants were excluded from subsequent analyses.

\section{Materials}

All video games were played on a Dell PC with specifications (e.g., RAM) exceeding those of the game requirements. The violent video game used in this study was House of the Dead 2 (1999; HOTD2), and the nonviolent video game was Kayak Extreme (2001). HOTD2 is a first-person shooter game in which the object is for the player to shoot and kill zombies and assorted demonic creatures. Participants fired a handheld PC USB light-gun (Act-Labs, 2002), which has the look and feel of a silver snub-nosed weapon, during this game. The video game was fixed using a "trainer" (i.e., an independently run computer program), such that participants had an unlimited number of lives. This was done in an effort to reduce game-related frustration from "dying." Furthermore, it allowed participants to play for 15 min without having to restart the game. In addition, the color of the blood depicted in the game was changed from green (the default color) to red using a "blood patch" (a computer program). HOTD2 contains frequent violent acts and excessive gore (e.g., heads exploding, arms shot off, lots of blood). Participants kill hundreds of zombies and demonic creatures while playing the game during the experiment. 
Kayak Extreme involves players kayaking down rapids in three different world locations. This game was rigged using a trainer to prevent disqualifications from missing "time gates" while proceeding down a rapids. This allowed participants to kayak down different rapids instead of repeating the same rapid over and over again. In addition, fixing the game helped reduce game-related frustration resulting from failing to complete the course due to disqualification as a result of missing too many gates.

Video game history. Participants were asked to rate how often they play video games on a 7-point Likert-type scale ranging from 1 (rare) to 7 (often).

Video game rating form. Participants rated the level of violence in their assigned video game. Furthermore, given the link between frustration and aggression (Berkowitz, 1962), the overall level of frustration experienced while playing the experimental video game was measured. Each question involved a 7-point Likert-type scale ranging from 1 (uncharacteristic) to 7 (characteristic).

Predispositional anger. Participants' propensity to respond to a variety of situations with anger was assessed using the BDHI. The BDHI consists of 75 true-false questions made up of seven subscales and a total hostility score. Studies using the total score on the BDHI as a global measure of hostility have found that high scorers retaliated sooner and delivered significantly more and stronger shocks to another person than low scorers in an experimental aggression situation (Knott, 1970) and that they perceived significantly more aggression than low scorers in a binocular rivalry situation (Petzel \& Michaels, 1973). Median splits were used to create high hostility and low hostility variables.

Emotional Stroop task. The GMST presents colored words in the center of a 20-color circular palette. Respondents click on a circle in the center of the screen to initiate the presentation of a stimulus word. After a colored word is presented, the participant moves the mouse to the corresponding color in the circular palette and clicks. Following the click, a circle appears in the center of the screen. This procedure is repeated for each stimulus word. The RT and selected color are recorded for each word. In the GMST, word color pairs are presented in a random order. For each individual, the dependent variable, "Stroop," was created by subtracting the average RT for correctly identified neutral words from the average RT for correctly identified negatively valenced words.

Stimulus words. The 20 negatively valenced and 20 neutral words used in this experiment (and in the training session) were previously used in research conducted by Sharma and McKenna (2001). The training words were ROSE, CURVE, CALL, WILLOW, FAIL, GLOOM, FIRE, and SORROW. For the ex- 
perimental condition, the neutral words were GATE, NOTE, CLOCK, THUMB, FIELD, LEVER, LEAGUE, WIRE, BREAD, AUTUMN, ANCHOR, SHOP, NAVAL, SENIOR, EXCEED, LINK, PLATE, DIVIDE, CALL, and FOOT. The negatively valenced words in the experimental condition were FEAR, CRASH, GRIEF, DEATH, PAIN, ANGRY, MURDER, HATE, SHOCK, CANCER, ENEMY, AFRAID, MISERY, EVIL, KILL, TRAGIC, THREAT, RAGE, PANIC, and BEATEN. Sharma and McKenna matched the stimulus words for length and frequency using Kucera and Francis (1967).

\section{RESULTS}

\section{Preliminary Analyses}

Video game history. Given that previous research has shown significant gender differences with regard to the frequency of video game play (Dill \& Dill, 1998; Funk \& Buchman, 1996), a chi-square analysis was used to determine if men and women differed in terms of their video game exposure. Results indicated a significant chi square, $\chi^{2}(6, N=129)=50.8, p<.0001$. Inspection of the contingency table revealed that, whereas $24 \%$ of men played video games frequently ( 6 or 7 on the Likert-type scale), none of the women reported frequent video game play. In contrast, whereas $77 \%$ of the women rarely played video games, only $17 \%$ of men rarely played. Furthermore, more men (59\%) played video games occasionally (3, 4 , or 5) than women $(23 \%)$. Given the wide range of video game experience, both within and between genders, experience with video games was entered as covariates in subsequent analyses.

Video game ratings. To verify that the violent and nonviolent video games were categorized correctly, a 2 (video game) analysis of variance (ANOVA) was conducted to test for differences in the perceived violence of the video games. Results indicated a significant main effect for video game, $F(1,113)=1226.2, p<$ $.0001, \eta^{2}=.92$, observed power $=1.0$, with HOTD2 $(M=6.1, S D=.8)$ being rated as significantly more violent than Kayak Extreme $(M=1.21, S D=.7)$.

To test for differences in the level of frustration involved with each video game, a 2 (gender) $\times 2$ (video game) ANOVA was conducted. Results indicated a significant main effect for gender, $F(1,113)=5.01, p<.05, \eta^{2}=.04$, observed power $=$ .61 , with women $(M=3.9, S D=1.5)$ finding the video games more frustrating than men $(M=3.3, S D=1.5)$. The main effect for video game and the Gender $\times$ Video Game interaction effect were both nonsignificant. Given these findings, frustration will be entered as a covariate in subsequent analyses. 


\section{Main Analyses}

Because RT data are subject to outliers, participant responses greater than three standard deviations above the mean were iteratively trimmed (Bowerman \& O'Connell, 1990). This resulted in a loss of $1.4 \%$ of neutral word trials and $1.6 \%$ of negative valenced word trials. Furthermore, as Weltford (1980) contended, only correct responses on RT tasks are valid; as such, individual RT averages were solely based on correct responses. This resulted in a loss of $7.7 \%$ and $6.9 \%$ of the neutral word and negatively valenced word trials, respectively.

To test the contention that violent video games affect an affect processing bias, a 2 (video game) $\times 2$ (trait hostility) $\times 2$ (gender) analysis of covariance was conducted, with previous experience playing video games and frustration associated with current video game play as the covariates. Results indicated significant main effects for video game, $F(1,113)=6.38, p<.05, \eta^{2}=.06$, observed power $=.71$, and trait hostility, $F(1,113)=4.24, p<.05, \eta^{2}=.04$, observed power $=.53$. Participants playing violent video games showed greater Stroop interference than participants playing nonviolent video games. Similarly, participants high in trait hostility showed greater Stroop interference than individuals low in trait hostility. The gender main effect and all interaction effects were nonsignificant. See Figure 1.

A series of planned contrasts was conducted to test the a priori prediction that individuals high in trait hostility playing violent video games would show the greatest Stroop interference. Results indicated partial support for the prediction. As Figure 1 illustrates, participants high in trait hostility playing the violent video game showed greater Stroop interference than individuals low in trait hostility

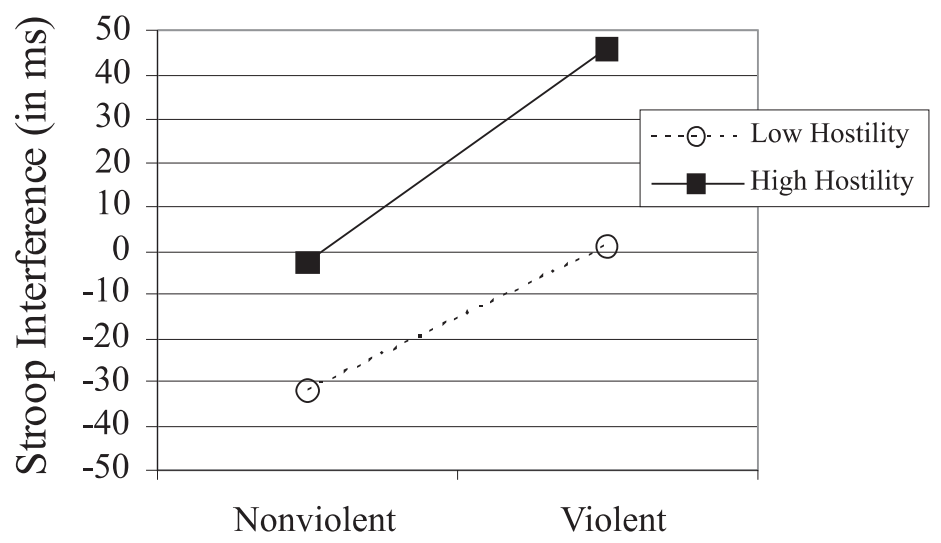

\section{Video Game}

FIGURE 1 Stroop interference (in millisecond) as a function of video game play and trait hostility. 
playing the violent video game, $t(58)=2.24, p<.05$. Similarly, participants high in trait hostility playing the violent video games demonstrated greater Stroop interference than individuals low in trait hostility playing the nonviolent video game, $t(58)=3.36, p<.001$. The contrast comparing individuals high in trait hostility playing the violent video game versus individuals high in trait hostility playing the nonviolent video game was marginally significant, $t(58)=1.84, p=.07$.

\section{DISCUSSION}

The results of this study found that participants high in trait hostility showed greater emotional Stroop interference than individuals low in trait hostility. These findings are consistent with previous assessments of attentional bias that have demonstrated links between psychopathology (e.g., panic disorder, generalized anxiety disorder, depression), personality characteristics (e.g., anxiety, trait anger), and mood congruent stimuli (e.g., threat words; see Eckhardt \& Cohen, 1997; Egloff \& Hock, 2000). Furthermore, these findings support Anderson and Bushman's (2002) GAM model contention that person variables (e.g., high in trait hostility) may bias social information processing. As Bower (1981) suggested, mood congruent information appears to "pop-out" at the perceiver, thus rendering that information harder to ignore.

Although only partial support was found for our a priori predictions involving the interaction of video game play and trait hostility, the data trended toward significance in the predicted direction, with individuals high in trait hostility and playing violent video games showing the greatest amount of Stroop interference. Although intriguing, the data are not strong enough to resolve the conflict in the literature associated with the interaction of violent video game play and trait hostility. As such, more research is warranted.

Independent of trait hostility, we found that violent video games appear to induce an affect processing bias in that participants playing the violent video game showed greater Stroop interference than individuals playing the nonviolent video game. The results of this study are consistent with earlier work finding relations between exposure to violent media and aggressive biases in social information processing (Anderson \& Dill, 2000; Bushman \& Geen, 1990; Kirsh, 1998; Kirsh \& Olczak, 2002; Lynch et al., 2001). For instance, Bushman (1998) found that playing violent video games resulted in faster RT when identifying strings of letters as words or nonwords in a lexical decision task.

Additional research on social information processing has found that playing violent video games increases the likelihood of inferring hostile intent to the actions of another, even though the intent of that individual is unclear (Kirsh, 1998). Thus, one possibility for the increase in aggressive behavior following video game play (Anderson \& Bushman, 2001) is that there is a greater likelihood of responding to 
a variety of provocation situations with aggression. In fact, research has demonstrated that individuals who are depressed (Quiggle, Garber, Panak, \& Dodge, 1992) or are high in trait anger (Kirsh \& Olczak, 2000) interpret ambiguous provocation situations (i.e., an individual gets hurt, but the intent of the provocateur may be either benign or malevolent) as stemming from hostile intent. Consistent with this finding that violent video game exposure influences attentional bias, research on mood congruent memory suggests that individuals with a negative mood are more likely to remember negatively valenced information better than other emotionally valenced information (Fiedler, Nickel, Muehlfriedel, \& Unkelbach, 2001). Together, these findings suggest that violent video game play renders aggressive stimuli more salient, resulting in biased attention, cognition, and memory.

In addition, the affectively negative attentional bias illustrated in this study may increase the likelihood of acting aggressively in situations involving aggressive scripts. Huesmann (1988) contended that, in response to experiences with aggressive stimuli and behavior (including the observation of aggressive acts performed by others), individuals develop aggressive scripts. These scripts contain information regarding the participants and events surrounding the aggressive act, such as the nature of the provocation and subsequent response. The results of this study suggest that exposure to violent video games biases attention toward negatively valenced information, potentially triggering already developed aggressive scripts. Thus, in combination with aggressive scripts, violent video game-induced attentional biases may increase the likelihood of acting aggressively.

It should be stated, however, that exposure to violent media is just one of many factors that influence aggressive behavior (Kirsh, 2003). Multiple factors have been shown to contribute to aggressive behavior across the life span. Family (e.g., low parental involvement, verbal and physical aggression), peer (e.g., aggressive or nonaggressive, popularity), school (e.g., achievement, dropout status), and personality (e.g., self-esteem, trait hostility) factors have all been linked to aggression (Leschied, Cummings, Van Brunschot, Cunningham, \& Saunders, 2000). Garbarino (1999) contended that the number of risk factors present is an important determinant of aggression. It may be that violent video games primarily impact the aggressive behavior of individuals who already have a certain number of risk factors associated with aggression (e.g., impulsivity, violent home, aggressive peer group).

In support of this contention, our data indicated that participants high in trait hostility (Risk Factor 1) playing violent video games (Risk Factor 2) showed the greatest level of Stroop interference. In contrast, individuals without these risk factors may face less of a risk of increasing their aggressive behavior by playing violent video games. Our data support this as well, in that individuals low in trait hostility playing violent video game showed less Stroop interference than those individuals high in trait hostility playing violent video games. This research is consistent with Eckhardt and Cohen's (1997) finding that, after being insulted (an en- 
vironmental experience), individuals' high in trait hostility, but not low in trait hostility, showed the longest color-naming latencies for angry words. In addition, our data are consistent with Bushman's (1996) finding that individuals high in trait aggressiveness have more well-developed aggressive cognitive-associate networks, in that associations between ambiguous and aggressive words were the strongest for individuals high in trait aggressiveness. Of note, the level of Stroop interference between those low in trait hostility playing violent video games was similar to that of individuals high in trait hostility playing nonviolent video games. Thus, video games appear to bias the processing of negatively valenced information for low hostile individuals to levels evident for high hostile individuals not exposed to violent video games. These data support the GAM proposition that activation of present internal state variables influences aggression-related responding, regardless of whether the source of the activation comes from person-based variables (such as trait hostility) or situational factors (such as violent video game play).

Several caveats to this study need to be mentioned. First, the results were found using a small sample of video games, thus potentially limiting the generalizability of the findings (Wells \& Windschitl, 1999). Second, it is possible that the violent and nonviolent video games differed in levels of arousal. Although frustration (a proxy for frustration-induced arousal) was statistically removed from the analyses, it is possible that additional factors influencing arousal (such as game play excitement and motor activity) affected RTs during the GMST. Future research should assess the independent and interactive contributions of arousal and violent video game play in social cognitive biases. Finally, although current level of video game play was assessed, long-term violent video game play and general preference and exposure to violent media (e.g., movies and TV) was not. Thus, the possibility exists that many of the participants entered the study desensitized to violent content. It is possible, therefore, that responses on the GMST vary as a function of long-term exposure to violent media and concomitant level of desensitization. This is an area for future research.

In conclusion, the processing of negatively valenced information appears to be affected by both personality factors such as trait hostility and environmental factors such as violent video games. Additional research is necessary, however, to determine how long after playing violent video games the affect bias lasts. It may be that the effects of this attentional bias last longer in individuals who are dispositionally hostile than in those who are not. Finally, these findings underscore current theories of aggression (e.g., Anderson \& Bushman, 2002) that emphasize the complex role that both situational and individual difference variables play in determining aggressive behavior. 


\section{REFERENCES}

Act-Labs. (2002). PC USB light gun [Online]. (Available from http://www.act-labs.com/Products/ gun1.htm)

Anderson, C. A. (2000). Violent video games increase aggression and violence. U.S. Senate Committee on Commerce, Science, and Transportation hearing on "The Impact of Interactive Violence on Children". Retrieved March 21, 2000, from http://psych-server.iastate.edu/faculty/caa/abstracts/ 2000-2004/00Senate.html

Anderson, C. A., \& Bushman, B. J. (2001). Effects of violent video games on aggressive behavior, aggressive cognition, aggressive affect, physiological arousal, and prosocial behavior: A meta-analytic review of the scientific literature. Psychological Science, 12, 353-359.

Anderson, C. A., \& Bushman, B. J. (2002). Human aggression. Annual Review of Psychology, 53, $27-51$.

Anderson, C. A., \& Dill, K. E. (2000). Video games and aggressive thoughts, feelings, and behavior in the laboratory and in life. Journal of Personality and Social Psychology, 78, 772-790.

Ballard, M. E., \& Lineberger, R. (1999). Video game violence and confederate gender: Effects on reward and punishment given by college males. Sex Roles, 41, 541-548.

Berkowitz, L. (1962). Aggression: A social-psychological analysis. New York: McGraw-Hill.

Bower, G. H. (1981). Mood and memory. American Psychologist, 36, 129-148.

Bowerman, B. L., \& O'Connell, R. T. (1990). Linear statistics model: An applied approach. Boston: PWS-Kent.

Bushman, B. J. (1996). Individual differences in the extent and development of aggressive cognitive-associative networks. Personality and Social Psychology Bulletin, 22, 811-819.

Bushman, B. J. (1998). Priming effects of media violence on the accessibility of aggressive constructs in memory. Personality and Social Psychology Bulletin, 24, 537-545.

Bushman, B. J., \& Anderson, C. A. (2001). Media violence and the American public: Scientific facts versus misinformation. American Psychologist, 56, 477-489.

Bushman, B. J., \& Geen, R. G. (1990). Role of cognitive-emotional mediators and individual differences in the effects of media violence on aggression. Journal of Personality and Social Psychology, $58,156-163$.

Buss, A. H., \& Durkee, A. (1957). An inventory for assessing different kinds of hostility. Journal of Consulting Psychology, 21, 343-349.

Cesarone, B. (1998). Video games: Research, ratings, recommendations. (ERIC Digest No. EDOPS-98-11). (ERIC Document Reproduction Service No. ED424038).

Dill, K. E., \& Dill, J. C. (1998). Video game violence: A review of the empirical literature. Aggression and Violent Behavior, 3, 407-428.

Eckhardt, C. I., \& Cohen, D. J. (1997). Attention to anger-relevant and irrelevant stimuli following naturalistic insult. Personality and Individual Differences, 23, 619-629.

Egloff, B., \& Hock, M. (2001). Interactive effects of state anxiety and trait anxiety on emotional Stroop interference. Personality and Individual Differences, 31, 875-882.

Fiedler, K., Nickel, S., Muehlfriedel, T., \& Unkelbach, C. (2001). Is mood congruency an effect of genuine memory or response bias? Journal of Experimental Social Psychology, 37, 201-214.

Fling, S., Smith, L., Rodriguez, T., Thornton, D., Atkins, E., \& Nixon, K. (1992). Video games, aggression, and self-esteem: A survey. Social Behavior and Personality, 20, 39-46.

Funk, J. B. (2000). The impact of interactive violence on children. U.S. Senate Committee on Commerce, Science, and Transportation hearing on "The Impact of Interactive Violence on Children." Retrieved March 21, 2000, from http://www.utoledo.edu/ psychology/funktestimony.html

Funk, J. B., \& Buchman, D. D. (1996). Playing violent video and computer games and adolescent self-concept. Journal of Communication, 46(2), 19-32.

Garbarino, J. (1999). Lost boys: Why our sons turn violent and how we can save them. New York: Free Press. 
Genov, A., Shay, I., \& Boone, R. T. (2002). Genov Modified Stroop Task [Online]. Retrieved February 14, 2002, from http://facpub.stjohns.edu/ booner/GmstSite/index.htm

Griffiths, M. D., \& Hunt, N. (1995). Computer games playing in adolescence: Prevalence and demographic indicators. Journal of Community and Applied Social Psychology, 5, 189-193.

House of the dead 2 [Video game]. (1999). Tokyo, Japan: Sega.

Huesmann, L. R. (1988). An information processing model for the development of aggression. Aggressive Behavior, 14, 13-24.

Irwin, R. A., \& Gross, A. M. (1995). Cognitive tempo, violent video games, and aggressive behavior in young boys. Journal of Family Violence, 10, 337-350.

Kayak extreme [Video game]. (2001). Surrey, England: Small Rockets.

Kirsh, S. J. (1998). Seeing the world through "Mortal Kombat" colored glasses: Violent video games and the development of a short-term hostile attribution bias. Childhood, 5, 177-184.

Kirsh, S. J. (2003). The effects of violent video game play on adolescents: The overlooked influence of development. Aggression and Violent Behavior: A Review Journal, 8, 377-389.

Kirsh, S. J., \& Olczak, P. V. (2000). Violent comic books and perceptions of ambiguous provocation situations. Media Psychology, 2, 47-62.

Kirsh, S. J., \& Olczak, P. V. (2002). The effects of extremely-violent comic books on social information processing. Journal of Interpersonal Violence, 17, 1830-1848.

Klinkenborg, V. (2002, December 16). Editorial observer; living under the virtual volcano of video games this holiday season. The New York Times [Online]. Retrieved April 25, 2002, from http://www.nytimes.com

Knott, P. D. (1970). A further methodological study of the measurement of interpersonal aggression. Psychological Reports, 26, 807-809.

Kucera, H., \& Francis, W. (1967). Computational analysis of present-day American English. Providence, RI: Brown University Press.

Leschied, A. W., Cummings, A., Van Brunschot, M., Cunningham, A., \& Saunders, A. (2000). Female adolescent aggression: A review of the literature and the correlates of aggression. Report for the Solicitor General of Canada [Online]. Retrieved March 25, 2002, from http://www.sgc.gc.ca

Lynch, P. J., Gentile, D. A., Olson, A. A., \& van Brederode, T. M. (2001, April). The effects of violent video game habits on adolescent aggressive attitudes and behaviors. Paper presented at the biennial conference of the Society for Research in Child Development, Minneapolis, MN.

Petzel, T. P., \& Michaels, E. J. (1973). Perception of violence as a function of levels of hostility. Journal of Consulting and Clinical Psychology, 41, 35-36.

Quiggle, N. L., Garber, J., Panak, W. F., \& Dodge, K. A. (1992). Social information processing in aggressive and depressed children. Child Development, 63, 1305-1320.

Sharma, D., \& McKenna, F. P. (2001). The role of time pressure on the emotional Stroop task. British Journal of Psychology, 92, 471-481.

Stroop, J. R. (1935). Studies of interference in serial verbal reactions. Journal of Experimental Psychology, 18, 643-662.

Wells, G. L., \& Windschitl, P. D. (1999). Stimulus sampling and social psychological experimentation. Personality and Social Psychology Bulletin, 25, 1115-1125.

Weltford, A. T. (1980). Reaction times. New York: Academic. 
Copyright of Media Psychology is the property of Lawrence Erlbaum Associates and its content may not be copied or emailed to multiple sites or posted to a listserv without the copyright holder's express written permission. However, users may print, download, or email articles for individual use. 